\title{
A IMPLEMENTAÇÃO DAS COMISSÕES DE HETEROIDENTIFICAÇÃO COMPLEMENTAR NO CEFET-MG
}

\author{
Aline de Carvalho Pereira ${ }^{1}$ \\ Natalino Neves da Silva ${ }^{2}$
}

\begin{abstract}
RESUMO
Este artigo busca compreender o processo de implementação das comissões de heteroidentificação complementar realizado no Centro Federal de Educação Tecnológica de Minas Gerais (CEFET-MG), unidade Nepomuceno. Para tal, a análise documental foi o principal recurso metodológico utilizado. Foram analisados os seguintes documentos: relatórios anuais emitidos internamente pela Coordenação de Registro e Controle Acadêmico, registros dos procedimentos utilizados pelas comissões, editais de processos seletivos, campanhas publicitárias, materiais veiculados nos cursos de capacitação, legislações pertinentes ao tema, entre outros. O estudo revelou que a implementação dessas comissões significou uma verdadeira conquista para a efetivação das políticas afirmativas na instituição.
\end{abstract}

Palavras-chave: Políticas de Ações Afirmativas. Educação Profissional. Direito à Educação.

\section{IMPLEMENTATION OF COMPLEMENTARY HETEROIDENTIFICATION COMMITTEES IN CEFET-MG}

\begin{abstract}
This article seeks to understand the process of implementing the complementary hetero-identification commissions carried out at the Federal Center for Technological Education of Minas Gerais (CEFETMG), Nepomuceno unit. For this, the documentary analysis was the main methodological resource used. The following documents were analyzed: annual reports issued internally by the Academic Registration and Control Coordination, records of the procedures used by the commissions, notices of selection processes, advertising campaigns, materials published in the training courses, legislation relevant to the topic, among others. The study revealed that the implementation of these commissions meant a real achievement for the effectiveness of affirmative policies in the institution.
\end{abstract}

Keywords: Affirmative Action Policies. Professional Education. Right to Education.

\section{IMPLEMENTACIÓN DE COMITÉS COMPLEMENTARIOS DE} HETEROIDENTIFICACIÓN EN CEFET-MG

\section{RESUMEN}

Este artículo busca comprender el proceso de implementación de las comisiones complementarias de heteroidentificación que se realizan en el Centro Federal de Educación Tecnológica de Minas Gerais (CEFET-MG), unidad Nepomuceno. Para ello, el análisis documental fue el principal recurso metodológico utilizado. Se analizaron los siguientes documentos: memorias anuales emitidas internamente por la Coordinación de Registro y Control Académico, registros de los procedimientos utilizados por las comisiones, avisos de procesos de selección, campañas publicitarias, materiales

\footnotetext{
1 Mestra em Educação, Servidora Técnico-Administrativa (CEFET-MG), unidade Nepomuceno. Email: alinepereira@ufsj.edu.br

2 Doutor em Educação, Professor da Faculdade de Educação da Universidade Federal de Minas Gerais (FaEUFMG). Email: professornatalino@gmail.com
} 
Pereira, A. de C.;Silva, N. N. da

publicados en los cursos de capacitación, legislación relevante en el tema, entre otros. El estudio reveló que la implementación de estas comisiones significó un verdadero logro para la efectividad de las políticas afirmativas en la institución.

Palabras clave: Políticas de acción afirmativa. Educación profesional. Derecho a la educación.

\section{UM INÍCIO DE CONVERSA}

Este artigo busca compreender o processo de implementação das comissões de heteroidentificação complementar realizado no Centro Federal de Educação Tecnológica de Minas Gerais (CEFET-MG), unidade Nepomuceno ${ }^{3}$. Diversos estudos têm apontado que a criação dessas comissões pela administração pública: “[...] se impôs como uma exigência do próprio processo de implementação da política de reserva de vagas. Se revelou como uma demanda necessária da própria política pública, diante da disputa de um bem raro que é uma vaga numa universidade [ensino técnico] ou um emprego público". (SANTOS; CAMILLOTO; DIAS; 2019, p. 37)

A Lei $\mathrm{n}^{\mathrm{o}}$ 12.711/2012 regulamenta o sistema de reserva de vagas de 50\% para candidatos(as) pretos, $\operatorname{pardos}^{4}$ e indígenas oriundos de escola pública, em proporção de no mínimo igual a constituição da população da unidade da Federação onde se encontra instaurada as instituições, de acordo com os dados organizados pelo último censo do Instituto Brasileiro de Geografia e Estatística (IBGE) (BRASIL, 2012).

O diagrama exposto na Figura 1 mostra o modo como deve ocorrer a distribuição das vagas a partir de um exemplo do número de 100 vagas no curso, divididos da seguinte forma:

\footnotetext{
${ }^{3}$ Parte das reflexões aqui desenvolvidas resulta da dissertação de Mestrado em Educação (PEREIRA, 2020). Para a realização das análises contidas neste artigo ora recorremos aos documentos produzidos na sede do CEFET-MG, ora tratamos especificamente das experiências e registros construídos na instituição investigada CEFET-MG, unidade Nepomuceno. Esse campus está localizado na região do sul de Minas e oferta cursos de graduação, presencial e a distância de ensino técnico integrado em nível médio. Em todos eles é destinado o percentual de $50 \%$ para as modalidades de reservas de vagas.

${ }^{4}$ Entende-se negro como uma categoria analítica constituída por pessoas que se autodeclaram como pretas e pardas conforme levantamento censitário realizado pelo IBGE.
} 
Figura 01- Distribuição das Reservas de Vagas

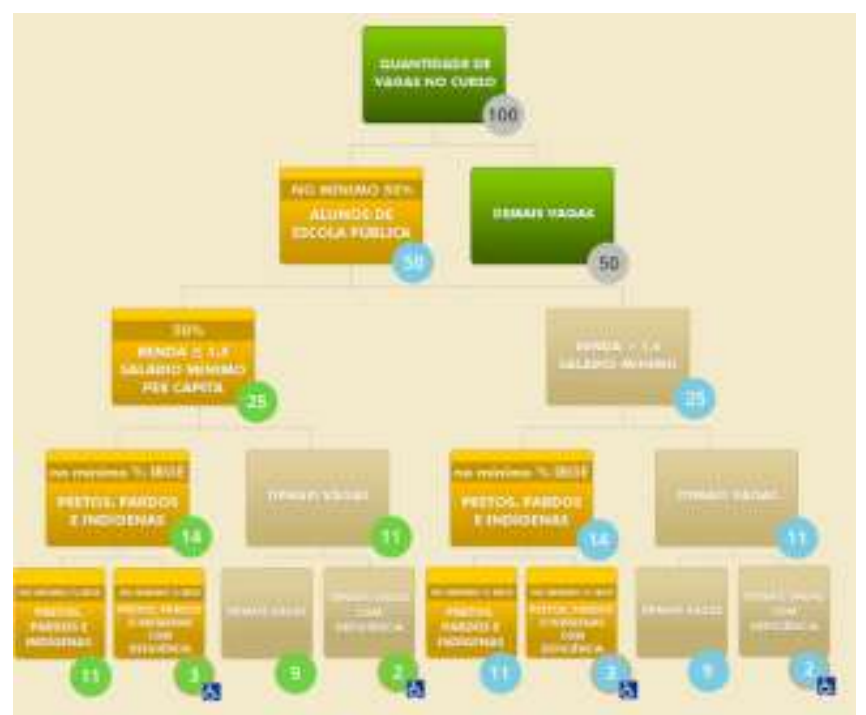

Fonte: http://portal.mec.gov.br/cotas/sobre-sistema.html

Apesar de não haver procedimentos padrões previamente definidos verificou que a atuação das comissões causou significativa mudança institucional quanto à: elaboração dos editais dos processos seletivos, oferta de capacitações, acolhida dos(as) estudantes e de seus responsáveis, infraestrutura, discussões e debates acerca da relações étnico-raciais, entre outros.

Contudo, nem sempre essa atuação é compreendida inclusive pelos próprios profissionais que ali atuam. Assim sendo, realizar o trabalho de heteroidentificação complementar em um contexto social estruturado pelo racismo à brasileira (MUNANGA, 2017, TELLES, 2003, GUIMARÃES, 2004) exige ao mesmo tempo seriedade, compromisso e ética em sua condução e concomitante a tarefa de reeducar para as relações étnico-raciais ${ }^{5}$, visto que:

[...] a autodeclaração requer interpretação cuidadosa, livre de preconceitos ou desconfianças prévias de dolo maldoso ou simulação quando legitimamente questionada a identidade autoatribuída, dada a complexidade do fenômeno identitário, onde um mesmo indivíduo pode experimentar uma multiplicidade de identidades nos diversos ambientes em que vive e transita, num mesmo momento ou ao longo de sua trajetória de vida. (RIOS, 2018, p.214)

Neste estudo, a análise documental foi o principal recurso metodológico utilizado. Foram analisados os seguintes documentos: relatórios anuais emitidos internamente pela

\footnotetext{
${ }^{5}$ Raça é aqui entendida enquanto uma construção científica, sociocultural e política. Para Guimarães (2003, p.96), a sociologia deve compreendê-la como "discursos sobre as origens de um grupo, que usam termos que remetem à transmissão de traços fisionômicos, qualidades morais, intelectuais, psicológicas, etc., pelo sangue" os quais geralmente dizem respeito às identidades sociais coletivas.
} 
Pereira, A. de C.;Silva, N. N. da

Coordenação de Registro e Controle Acadêmico, registros dos procedimentos utilizados pelas comissões, editais de processos seletivos, campanhas publicitárias, materiais veiculados nos cursos de capacitação, legislações pertinentes ao tema, entre outros.

No desenvolvimento do estudo nos demos conta de que a escolha dessa metodologia contribuiu para, entre outras coisas, assegurar a memória relacionada ao processo de implementação dessas comissões. Sabe-se que nem sempre os registros institucionais produzidos são tratados e analisados como fontes documentais. É por esse motivo que a análise documental se apresentou como uma “[...] técnica valiosa de abordagem de dados qualitativos, seja complementando as informações obtidas por outras técnicas, seja desvelando aspectos novos de um tema ou problema”. (ANDRÉ; LÜDKE, 1986, p. 38)

$\mathrm{O}$ artigo está dividido em dois tópicos, além dessa introdução e das considerações finais. No primeiro deles, busca situar o conjunto de regulamentações existentes que norteiam os procedimentos de heteroidentificação. No segundo, é reconstituído o processo de implementação das comissões no CEFET-MG, a partir dos documentos analisados. Nas considerações finais, destaca-se a importância da atuação das comissões para a consolidação das políticas afirmativas.

\section{COMISSÕES DE HETEROIDENTIFICAÇÃO COMPLEMENTAR}

De 2001 até meados de 2012, ou seja, antes mesmo da obrigatoriedade exposta pela referida Lei, já havia várias universidades públicas federais, estaduais e municipais, com algum tipo de reserva de vaga sob a forma de cotas ou de bônus e com diferentes modalidades (cotas para negros ou indígenas, cotas para estudantes oriundos de escola pública, para pessoas com deficiência, quilombolas, mulheres, refugiados, etc.).

Contudo, as comissões de heteroidentificação complementar ${ }^{6}$ passaram atuar no contexto da Lei $\mathrm{n}^{\mathrm{o}}$ 12.711, conhecida popularmente como Lei de Cotas e, após as orientações do Ministério Público ${ }^{7}$ que tinham como intenção assegurar de fato a implantação das políticas de ações afirmativas nas instituições.

Como podemos observar na tabela 1 , já existe um conjunto de regulamentações que contribuem para nortear a realização dos procedimentos de heteroidentificação. Destacam-se entre elas, as decisões proferidas pelo Supremo Tribunal Federal no que concerne a Arguição

\footnotetext{
${ }^{6}$ Osório explicita que há três métodos de identificação racial, que podem ser aplicados com variantes. O primeiro é a autoatribuição de pertença, no qual o próprio sujeito da classificação escolhe o grupo do qual se considera membro. O segundo é a heteroatribuição de pertença, no qual outra pessoa define o grupo do sujeito. O terceiro método é a identificação de grandes grupos populacionais dos quais provieram os ascendentes próximos por meio de técnicas biológicas, como a análise do DNA (OSÓRIO, 2003, p.7-8).

${ }^{7}$ Cabe ressaltar as portarias relacionadas à necessidade de criação das comissões emitidas pelo Ministério do Planejamento, Desenvolvimento e Gestão de Pessoas (MPOG), além de nortearem o trabalho realizado, elas contribuíram também como fundamentação jurídico-administrativa.
} 
Pereira, A. de C.;Silva, N. N. da

de Descumprimento de Preceito Fundamental (ADPF) n ${ }^{\circ} 186$ e a Ação Declaratória de Constitucionalidade (ADC) $n^{\circ} 41$ ao reconhecer, em ambas, a constitucionalidade da política de ações afirmativas.

E a Portaria Normativa n. ${ }^{\circ}$, de 6 de abril de 2018, do Ministério do Planejamento, Desenvolvimento e Gestão de Pessoas (MPOG) como sendo alguns dos principais dispositivos legais que fundamentam a realização deste trabalho.

Tabela 01 - Legislações que norteiam as Comissões

\begin{tabular}{|c|c|c|c|c|c|}
\hline TIPO & $\mathbf{N}^{0}$ & ANO & ASSUNTO & RESPONSÁVEL & $\begin{array}{c}\text { LINK } \\
\text { CURTO }\end{array}$ \\
\hline Normativa & 4 & 2018 & $\begin{array}{l}\text { Regulamenta o procedimento de } \\
\text { heteroidentificação } \\
\text { complementar à autodeclaração } \\
\text { dos candidatos negros, para fins } \\
\text { de preenchimento das vagas } \\
\text { reservadas nos concursos } \\
\text { públicos federais, nos termos da } \\
\text { Lei n` }{ }^{\circ} 2.990 \text {, de } 9 \text { de junho de } \\
2014 .\end{array}$ & MPOG & $\frac{\text { https://goo.gl/ }}{\underline{\text { YzUfZ8 }}}$ \\
\hline Outros & \multicolumn{2}{|c|}{2017} & $\begin{array}{c}\text { Ação Declaratória de } \\
\text { Constitucionalidade }(A D C) \mathrm{n}^{\circ} 41 \\
\text { que reconhece a validade da Lei } \\
\mathrm{n}^{\mathrm{o}} 12.990 / 2014 \text {, que reserva } 20 \% \\
\text { das vagas oferecidas em } \\
\text { concursos públicos para } \\
\text { provimento de cargos efetivos e } \\
\text { empregos públicos. }\end{array}$ & $\begin{array}{c}\text { Supremo Tribunal } \\
\text { Federal }\end{array}$ & $\begin{array}{c}\text { https://bityli.co } \\
\text { m/dIZkI }\end{array}$ \\
\hline Recomendação & 41 & 2016 & $\begin{array}{l}\text { Define parâmetros para a atuação } \\
\text { dos membros do Ministério } \\
\text { Público brasileiro para a correta } \\
\text { implementação da política de } \\
\text { cotas étnico-raciais em } \\
\text { vestibulares e concursos } \\
\text { públicos. }\end{array}$ & $\begin{array}{c}\text { Conselho } \\
\text { Nacional } \\
\text { Ministério } \\
\text { Público }\end{array}$ & $\frac{\text { https://goo.gl/S }}{\text { q8B97 }}$ \\
\hline Portaria & 11 & 2016 & $\begin{array}{l}\text { Institui GT p/ discutir os } \\
\text { procedimentos de verificação da } \\
\text { autodeclaração. }\end{array}$ & $\begin{array}{c}\text { Ministérios } \\
\text { (MPOG+MJC) }\end{array}$ & $\frac{\text { https://goo.gl/z }}{\underline{\text { sJByM }}}$ \\
\hline Lei & 12.990 & 2014 & $\begin{array}{l}\text { Reserva aos negros } 20 \% \text { (vinte } \\
\text { por cento) das vagas oferecidas } \\
\text { nos concursos públicos para } \\
\text { provimento de cargos efetivos e } \\
\text { empregos públicos no âmbito da } \\
\text { administração pública federal, } \\
\text { das autarquias, das fundações } \\
\text { públicas, das empresas públicas e } \\
\text { das sociedades de economia } \\
\text { mista controladas pela União. }\end{array}$ & Brasil & $\frac{\underline{\text { https://goo.gl/ }}}{\text { Gjx85Z }}$ \\
\hline Outros & 20 & & $\begin{array}{l}\text { Convenção Interamericana } \\
\text { contra o Racismo. }\end{array}$ & OEA (OAS) & $\frac{\text { https://goo.gl/ }}{\text { ECb8pL }}$ \\
\hline
\end{tabular}


Pereira, A. de C.;Silva, N. N. da

\begin{tabular}{|c|c|c|c|c|c|}
\hline Outros & \multicolumn{2}{|c|}{2012} & $\begin{array}{l}\text { Decisão proferida pelo Supremo } \\
\text { Tribunal Federal na Arguição de } \\
\text { Descumprimento de Preceito } \\
\text { Fundamental (ADPF) no } 186 \text { que } \\
\text { considerou constitucional a } \\
\text { política de ações afirmativas. }\end{array}$ & $\begin{array}{l}\text { Supremo Tribunal } \\
\text { Federal }\end{array}$ & $\begin{array}{l}\text { https://bityli.co } \\
\text { m/ZA7ZR }\end{array}$ \\
\hline Lei & 12.711 & 2012 & $\begin{array}{l}\text { Dispõe sobre o ingresso nas } \\
\text { universidades federais e nas } \\
\text { instituições federais de ensino } \\
\text { técnico de nível médio e dá } \\
\text { outras providências. }\end{array}$ & Brasil & $\frac{\text { https://goo.gl/k }}{\underline{\mathrm{RgFeG}}}$ \\
\hline Lei & 12.288 & 2010 & $\begin{array}{l}\text { Institui o Estatuto da Igualdade } \\
\text { Racial. }\end{array}$ & Brasil & $\frac{\text { https://goo.gl/1 }}{\underline{\text { BzKot }}}$ \\
\hline Decreto & 7.037 & 2009 & $\begin{array}{c}\text { Aprova o Programa Nacional de } \\
\text { Direitos Humanos. }\end{array}$ & Brasil & $\frac{\text { https://goo.gl/j }}{\underline{\text { dszjr }}}$ \\
\hline Outros & & & $\begin{array}{c}\text { Conferência Mundial de } \\
\text { Combate ao Racismo } \\
\text { (Declaração de Durban, África } \\
\text { do Sul). }\end{array}$ & OEA (OAS) & $\frac{\text { https://goo.gl/ }}{\underline{\text { X2ScZV }}}$ \\
\hline $\begin{array}{l}\text { nst. Federal } \\
\text { Art. } 3^{\circ} \text {. }\end{array}$ & & & $\begin{array}{l}\text { Objetivos fundamentais da } \\
\text { República. }\end{array}$ & Brasil & $\frac{\text { https://goo.gl/ }}{\underline{\text { EfgAH2 }}}$ \\
\hline Decreto & 65.810 & 1969 & $\begin{array}{l}\text { Promulga a Convenção } \\
\text { Internacional sobre a Eliminação } \\
\text { de todas as Formas de } \\
\text { Discriminação Racial. }\end{array}$ & Brasil & $\frac{\text { https://goo.gl/d }}{\mathrm{jjEjj}}$ \\
\hline
\end{tabular}

Fonte: Inspirado em Tavares Junior (2018).

A validade da atuação das comissões é bastante explícita no documento da ADC $\mathrm{n}^{\mathrm{o}}$ 41/2017, por exemplo. O que revela a compatibilidade tanto da autodeclaração quanto da heteroideintificação étnico-racial complementar.

Quanto à autodeclaração, prevista no parágrafo único do art. $2^{\circ}$ da Lei federal 12.990/2014, o Supremo asseverou que se devem respeitar as pessoas tal como elas se percebem. Entretanto, um controle heterônomo não é incompatível com a Constituição, observadas algumas cautelas, sobretudo quando existirem fundadas razões para acreditar que houve abuso na autodeclaração. Assim, acrescentou que é legítima a utilização de critérios subsidiários de heteroidentificação para concorrência às vagas reservadas. A finalidade é combater condutas fraudulentas e garantir que os objetivos da política de cotas sejam efetivamente alcançados, desde que respeitada a dignidade da pessoa humana e assegurados o contraditório e a ampla defesa. Citou, como exemplos desses mecanismos, a exigência de autodeclaração presencial perante a comissão do concurso, a apresentação de fotos e a formação de comissões com composição plural para entrevista dos candidatos em momento posterior à autodeclaração (BRASIL, 2017). 
Pereira, A. de C.;Silva, N. N. da

Cabe ressaltar que poucas foram às instituições de ensino que haviam criado algum tipo de procedimento de verificação relacionado especificamente o sistema de reserva de vagas das cotas raciais. Nunes $(2018$, p. 18) reflete a esse respeito que:

[...] as comissões que têm a responsabilidade de garantir o acesso ao ensino superior e ao serviço público de pretos, pardos e indígenas. Valem-se da atividade de heteroidentificação orientadas nos editais do concurso e, a grande maioria, atua sob orientação da Portaria Normativa n. ${ }^{\circ} 4$, de 6 de abril de 2018, do Ministério do Planejamento, Desenvolvimento e Gestão de Pessoas que regulamenta o procedimento de heteroidentificação complementar à autodeclaração dos candidatos negros, para fins de preenchimento das vagas reservadas nos concursos públicos federais, nos termos da Lei no 12.990 , de 9 de junho de 2014. Até o presente momento, é o único dispositivo jurídico que orienta formas procedimentais para monitorar a autodeclaração étnico-racial e, por isso, tem sido utilizada também por universidades no ingresso através da 12.711/12.

As características fenotípicas, quais sejam: cor da pele, textura do cabelo, formato do rosto, lábios e nariz, etc., são adotadas como critérios de aferição porque são através delas é que incide o racismo, a discriminação e o preconceito étnico-racial. Na percepção de Vaz (2018, p. 39), “[...] se o fenótipo é o fator que, socialmente, determina o racismo - resultando na exclusão social da população negra - também este deve ser o critério para a definição dos destinatários das ações afirmativas de cunho racial”. Isso significa que as cotas raciais:

[...] devem ter aplicabilidade restrita às potenciais vítimas diretas do racismo e da discriminação racial. E para tanto, os membros das comissões de verificação, diante de um candidato(a) cotista, devem se perguntar se este apresenta um conjunto de características fenotípicas que permitam considerá-lo como negro(a), no contexto local (VAZ, 2018, p. 40).

Embasados nesta concepção, as comissões de verificação possuem um importante papel de defesa e proteção de direitos contra as fraudes e de fazer valer a finalidade para o qual as políticas de ações afirmativas foram instituídas.

\section{O PROCESSO DE IMPLEMENTAÇÃO DAS COMISSÕES DE HETEROIDENTIFICAÇÃO NO CEFET-MG}

As Comissões, em todas as unidades do CEFET-MG, foram constituídas através da Coordenadoria de Gênero, Relações Étnico-Raciais, Inclusão e Diversidades ${ }^{8}$ (CGRID), em colaboração com a Comissão Permanente de Vestibular (COPEVE), ambas responsáveis pela organização do processo de formação e atuação das comissões de heteroidentificação.

Em novembro de 2017, a CGRID e a COPEVE, com o apoio da Fundação CEFET Minas e do Núcleo de Pesquisa e Estudos Afro-Brasileiros (NEAB) promoveu o I Seminário sobre inclusão, diversidade e ações afirmativas na Rede Federal de Educação Profissional,

\footnotetext{
${ }^{8}$ A CGRID é coordenada pela professora doutora Silvani dos Santos Valentim. Ela foi fundada no ano de 2012 pela Diretoria de Extensão e Desenvolvimento Comunitário (DEDC).
} 
Pereira, A. de C.;Silva, N. N. da

Científica e Tecnológica de Minas Gerais que foi direcionado para os reitores, diretores gerais, gestores e servidores, entre outros.

No âmbito do Seminário aconteceu também um Workshop visando preparar servidores docentes e técnicos administrativos para atuarem na primeira comissão de heteroidentificação. Nele foram abordadas temáticas relacionadas às ações afirmativas, cotas sociais, cotas raciais, às comissões de aferição de candidatos(as) autodeclarados(as) pretos, pardos e indígenas, bem como foram compartilhadas experiências de outras instituições buscando compreender formas de organização e funcionamento.

No caso da composição das comissões do CEFET-MG, unidade Nepomuceno, ela era integrada por três membros titulares técnico-administrativos e três membros suplentes (dois docentes e um técnico administrativo) todos servidores efetivos da instituição. Na ocasião, verificou-se que poucos eram os docentes que abordavam a temática das relações étnicoraciais em suas disciplinas.

A recomendação dada pela CGRID acerca dos procedimentos a serem adotados dispunha em: preencher ficha de identificação, lançar os resultados de deferimento e indeferimento, via sistema disponibilizado pela COPEVE e constituir uma comissão recursal, entre outros.

Além dessas orientações, as entrevistas dos(as) candidatos(as) deveriam ser agendadas com antecedência, conforme o cronograma previamente organizado pela COPEVE, por meio das seguintes ferramentas: divulgação no site institucional, contato telefônico, etc.

A implantação das primeiras comissões trouxe consigo um cenário de desafios e mudanças institucionais. As recorrentes indagações acerca de concepções teóricas relacionadas ao campo das relações étnico-raciais eram inerentes ao longo de todo processo. Consequentemente, a realização desse trabalho revelou a necessidade permanente de investir em cursos de formação continuada direcionados à promoção da igualdade étnico-racial.

Essa realidade explicitou que a Educação das Relações Étnico-Raciais (ERER) na educação técnica e superior da instituição se dá de maneira bastante incipiente. Mesmo diante da exigência prevista na Lei $n^{\circ} 10.639 / 03$ e de suas diretrizes ${ }^{9}$, que trata da obrigatoriedade do ensino de História e Cultura afro-brasileira no currículo oficial, em escolas públicas e privadas, sendo posteriormente incluído o ensino de História e Cultura da população indígena, regulamentada por meio da Lei $n^{\circ} 11.645 / 08$ (BRASIL, 2008).

\footnotetext{
${ }^{9}$ Vale a pena consultar o Parecer $n^{\circ} .003 / 2004$ emitido pelo Conselho Nacional de Educação de 10 de março de 2004, que institui as Diretrizes curriculares nacionais para a educação das relações étnico-raciais e para o ensino de História e Cultura Afro-brasileira e Africana. Disponível em: https://bityli.com/gDTCP. Acesso em: 13 mar. 2015.
} 
Pereira, A. de C.;Silva, N. N. da

Conforme apontado na pesquisa de Silva (2019), quando a ERER é abordada no contexto da educação profissional ela se dá através dos núcleos relacionados às ciências humanas e sociais vinculados sobretudo a educação básica e superior. Essa constatação é preocupante, pois os estudos acerca das relações étnico-raciais têm apontado que o processo de implementação da Lei $n^{\circ}$. 10.639 e, consequentemente, as políticas afirmativas, só será efetivado com a participação de todos os profissionais da educação (gestores, docentes, técnico-administrativos, discentes, entre outros) (GOMES, 2012, MACEDO, 2020, MEINERZ; PEREIRA, 2018).

É importante entender nesse caso que as "cotas raciais" fazem parte de um conjunto de Políticas de Ações Afirmativas ${ }^{10}$, as quais, por conseguinte, estão inseridas em uma perspectiva de equidade sociorracial ${ }^{11}$. A conquista dessas políticas está inserida, portanto, a história de luta realizada pelo movimento negro e de uma rede solidária antirracista.

Nesse caso, as Políticas Afirmativas tem em vista reparar assimetrias sociorraciais e educacionais produzidas pelo racismo (GOMES, 2001). Elas têm contribuído, ainda, para reeducar a sociedade. Haja vista que a ideologia da meritocracia permanece bastante viva no ensino técnico e superior. Entretanto, essa ideologia com o passar dos anos tem sido cada vez mais tensionada por meio da adoção dessas políticas.

A análise dos registros coletados revela a importância do trabalho realizado pelas comissões a esse respeito. Foi o conhecimento adquirido através dele que possibilitou conceber e sistematizar parâmetros dos procedimentos a serem seguidos. O intercâmbio de informações e trocas de experiências compartilhadas em nível local, regional e nacional ${ }^{12}$ foram também cruciais para garantir a sua consolidação.

A promoção de momentos de escuta, de experimentação e de troca de conhecimentos foram fundamentais na implementação das bancas no CEFET-MG, contribuindo para identificar os procedimentos mais adequados para a sua atuação. Em 2016, por exemplo, aconteceu uma banca-piloto de verificação com os ingressantes dos cursos de graduação. Já em 2017, foi realizado o Seminário Regional de Inclusão e Diversidades na Rede Federal de Educação Profissional, Científica e Tecnológica, que contou com a participação de servidores de todos os campi e possibilitou ampliar a discussão com outras instituições, como a Universidade Federal de Ouro

\footnotetext{
${ }^{10}$ É possível considerar que: a Lei n ${ }^{\circ} 12.288 / 2010$ que institui o Estatuto da Igualdade Racial destinado a garantir à população negra a efetivação da igualdade de oportunidades, a Lei $\mathrm{n}^{\circ} 10.639 / 03$, alterada posteriormente para Lei $n^{\circ} 11.645 / 08$, a Lei $n^{\circ} 12.990 / 14$ a qual reserva aos candidatos negros(as) $20 \%$ das vagas oferecidas nos concursos públicos, entre outras, são medidas que estão alinhadas a concepção dessas políticas.

${ }^{11}$ Estudos realizados acerca das Políticas Afirmativas e Ensino Superior: CARVALHO, 2016, FERES JUNIOR; DAFLON; CAMPOS, 2012, MOEHLECKE, 2002, PIOVESAN, 2008, SANTOS, 2018, SILVA, 2020, SILVA; SILVÉRIO, 2003, entre outros. Cabe ressaltar que são incipientes as investigações relacionadas às ações afirmativas em interface com ensino técnico. De igual modo, sobre as comissões de heteroidentificação complementar tanto nesse nível de ensino como no superior.

${ }^{12}$ A Associação Brasileira de Pesquisadores/as Negros/as (ABPN), bem como o Consórcio Nacional de Núcleos de Estudos Afro-Brasileiros (CONNEABS) são interlocutores desse trabalho. Para saber mais: https://www.abpn.org.br/consorcio-de-neabs
} 
Pereira, A. de C.;Silva, N. N. da

Preto (UFOP). (Jornal Diagrama, Silvani Valentim coordenadora-geral da CGRID, 2018, p.9)

A Portaria expedida pela Diretoria Geral (DIR) $n^{\circ} 1079 / 18^{13}$, no ano de 2018, assegura que para a composição das comissões é preciso verificar: diversidade de gênero, étnico-racial e local, etc., bem como possibilita a participação da comunidade externa vinculada inclusive aos movimentos sociais na função de titulares.

Cabe ressaltar que nos casos de indeferimento, é resguardado ao(a) candidato(a) o direito de entrar com recurso, conforme em datas previstas no edital. Permanecendo a decisão de indeferimento, o(a) pretendente volta a disputar uma vaga na modalidade de ampla concorrência no caso do ensino técnico. Já no superior, o mesmo sujeita-se à eliminação do processo seletivo pelo Sistema de Seleção Unificada (SISU).

A análise do Memorando interno produzido por integrantes das comissões da unidade Nepomuceno enviado para a CGRID, no início de 2018, evidencia que a realização desta atuação exige ser constantemente aperfeiçoada. Nele há sugestões com vista aprimorar o processo em curso, tais como:

$\checkmark$ A necessidade de maior divulgação aos candidatos sobre os critérios fenotípicos, a serem avaliados no documento do edital, no decorrer da inscrição, ao acessar o sistema de cadastro e durante a divulgação dos processos seletivos.

$\checkmark$ A formação continuada para todos os membros da Comissão, visando à melhor compreensão do trabalho e à maior uniformidade nos processos de avaliação.

$\checkmark$ O aumento do quantitativo de integrantes da Comissão, considerando o trabalho do docente e do técnico-administrativo no setor de origem, férias, impedimentos pessoais.

$\checkmark$ A divulgação prévia no calendário das Comissões de Heteroidentificação, para a organização dos membros da comissão, decorrente do grande número de chamadas/candidatos e da organização de possíveis comissões recursais.

$\checkmark$ A possibilidade de inserção de membros de outras unidades.

$\checkmark$ A redução do número de horas disponíveis de avaliação aos candidatos, após a primeira chamada, visando à otimização do trabalho da Comissão e o período de permanência ociosa em prol das entrevistas.

$\checkmark$ A discussão mais detalhada dos critérios de avaliação referente à autodeclaração do "pardo" e da resposta da Comissão quanto ao deferimento/indeferimento.

13 O documento foi publicado no Boletim de Serviço e Pessoal (CEFET-MG). Disponível em: <https://www2.cefetmg.br/textoGeral/Boletim/boletim2018.html $>$. Acesso em: 01 nov. 2018. 
Pereira, A. de C.;Silva, N. N. da

$\checkmark$ O estabelecimento de canal de comunicação entre os membros da Comissão e a CGRID.

$\checkmark$ A necessidade em se obter dos candidatos, além da autodeclararão, a entrega para a Comissão de uma foto $3 \times 4$, visando à formação de um banco de informações de referência para a comissão sobre deferimentos/indeferimentos.

No mesmo ano, foram encaminhadas ainda novas propostas à CGRID, a partir de uma reunião realizada, com outras contribuições levantadas por essas comissões que foram expressas da seguinte forma:

$\checkmark$ Ampliação da divulgação do vídeo institucional criado pelo CEFET-MG, no edital interno, reforçando a importância da existência da comissão e os critérios a serem avaliados.

$\checkmark$ Configuração do sistema de acesso às inscrições para que o candidato seja direcionado à página do vídeo institucional sobre Ações afirmativas no CEFET-MG.

$\checkmark$ Reforçar a importância de a comissão julgadora de recursos contenha todos os membros distintos da primeira comissão de heteroidentificação.

$\checkmark$ Discussão mais detalhada, mediante treinamentos e capacitações sobre os critérios de avaliação do candidato pardo visando à qualificação e à uniformidade dos trabalhos.

No mesmo ano, a CGRID em parceria com a COPEVE realizou o $2^{\circ}$ Encontro preparatório para atuação nas comissões. Nesta segunda capacitação foi abordada a sua constituição em outras instituições, a proposta de gravar as entrevistas e a padronização dos formulários e perguntas feitas durante as entrevistas. Houve, também, um período de debate sobre a necessidade de maior compreensão em classificar o "pardo" e palestras sobre o racismo no Brasil.

De acordo com as orientações dadas pela CGRID, através da Portaria interna, o trabalho das Comissões deveria seguir os seguintes critérios de operacionalização:

$\checkmark$ A Comissão deve pautar-se única e exclusivamente em critérios fenotípicos por análise e verificação em entrevistas previamente agendadas com o candidato (presencial).

$\checkmark$ A ascendência do candidato não deve ser considerada como critério de análise para a aferição de cor/raça do candidato.

$\checkmark$ Os critérios fenótipos são aqueles que devem possibilitar, nas relações sociais estabelecidas, o mútuo reconhecimento do indivíduo como preto ou pardo. 
Pereira, A. de C.;Silva, N. N. da

$\checkmark$ Os candidatos autodeclarados indígenas devem apresentar comprovação de pertença étnica e social a um grupo ou comunidade mediante declaração emitida pela Fundação Nacional do Índio (FUNAI).

$\checkmark$ As decisões das Comissões devem ser registradas, em formulário próprio, validando ou invalidando a autodeclaração firmada pelo candidato, no ato da análise dos documentos.

Nessa perspectiva, o formulário de heteroidentificação apresentou mudanças drásticas em comparação ao anterior, de modo a apresentar de maneira detalhada legislações que regem o trabalho das comissões e o roteiro de como as entrevistas deveriam ser conduzidas.

Essas discussões e práticas voltadas para garantir a efetividade das ações afirmativas na instituição foram incorporadas no Edital $n^{\circ} 075 / 2017^{14}$. Nele consta as seguintes informações:

14.4 Além da análise documental e com o objetivo de certificar a regularidade das situações que habilitam os candidatos à concorrência pelo Sistema de Reserva de Vagas (SRV), a COPEVE poderá promover a. Para todas as modalidades: diligências, perícias e verificação de autenticidade junto a outros órgãos governamentais de documentos relativos à comprovação da condição de estudante com origem escolar e certificação nas condições elencadas no item 2.4, nos casos que a COPEVE julgar necessários; b. Para as modalidades que envolvem avaliação de renda: diligências, visitas em domicílio, entrevistas, perícias e verificação de autenticidade de documentos junto a outros órgãos governamentais, nos casos que a COPEVE julgar necessários; c. Para as modalidades que envolvem declaração de cor/etnia: entrevistas e assinatura do termo de autodeclaração na presença de comissão específica, para todos os aprovados nessas modalidades; d. Para as modalidades que envolvem a condição de pessoa com deficiência: entrevistas, perícias e avaliação técnica feita por comissão especializada, para todos os aprovados nessas modalidades.

No Edital $n^{0} 72 / 2018^{15}$ a atuação das comissões é ainda mais notabilizada revelando uma explícita preocupação de que o público em geral obtivesse pleno conhecimento acerca dos procedimentos adotados:

14.2 As Comissões de Verificação de Cor-Etnia serão formadas por 3 (três) membros, servidores do quadro permanente do CEFET-MG ou brasileiros natos de reputação ilibada, residentes no país e, preferencialmente, experientes na temática da promoção da igualdade racial e do enfrentamento ao racismo.

14.2.1 Um dos membros da comissão será o seu presidente.

\footnotetext{
${ }^{14}$ Comissão Permanente do Vestibular (COPEVE). Inscrição em processo seletivo. 2018. Disponível em: $<$ http://www.dcsa.cefetmg.br/2017/08/30/processo-seletivo-para-o-ensino-tecnico-edital-no752017/>. Acesso em: 13 dez. 2017.

15 Comissão Permanente do Vestibular (COPEVE). Inscrição em processo seletivo. 2019. Disponível em: $<$ https://www.copeve.cefetmg.br/processos/2019_TEC/arquivos/editais/edital-72-2018-ensino-tecnico-2019>. Acesso em: 18 set. 2019.
} 
14.2.2 No mínimo, 1 (um) dos integrantes da comissão deverá pertencer ao quadro de servidores ativos e permanentes do CEFET-MG. 14.3 As Comissões de Verificação de Cor-Etnia farão, nessa oportunidade, o procedimento de heteroidentificacão do candidato, o qual se constitui na identificação por terceiros da condição autodeclarada. 14.4 Para validar as informações sobre cor-etnia prestadas pelo candidato que se autodeclara negro (preto ou pardo), a Comissão de Verificação utilizar-se-á única e exclusivamente do fenótipo como base para análise e emissão de seu parecer.

14.4.1 O que orienta a aferição de cor-etnia negra (preto ou pardo) $\underline{\mathbf{N A} O}$ é a ascendência do candidato, ou seja, quem são os seus pais, avós ou bisavós, mas as características físicas (fenótipo) do próprio candidato. Além disso, $\underline{\mathbf{N A ̃ O}}$ serão considerados quaisquer registros (civis ou militares) ou documentos pretéritos (anteriores), eventualmente apresentados pelo candidato, referentes a procedimentos de heteroidentificação realizados por quaisquer outras instituições (públicas ou privadas), inclusive imagens, declarações ou certidões de qualquer natureza.

14.4.2 O fenótipo é definido como o conjunto de características do indivíduo, predominantemente a cor da pele, a textura do cabelo e os formatos do rosto, lábios e nariz, que combinados ou não, permitirão ratificar ou invalidar a autodeclaração. Serão consideradas as características fenotípicas do candidato ao tempo da realização do procedimento de heteroidentificação.

14.5 Para validar as informações sobre cor-etnia prestadas pelo candidato que se declara indígena, a Comissão de Verificação utilizar-se-á do fenótipo e do documento emitido pela Fundação Nacional do Índio (FUNAI) conforme exigido nos procedimentos da seção 13 acima e no Anexo VI como base para análise e emissão de seu parecer.

14.6 A Comissão de Verificação de Cor-Etnia deliberará pela maioria dos seus membros, sob forma de parecer motivado.

14.6.1 As decisões da Comissão de Verificação de Cor-Etnia serão registradas em formulário próprio e o conhecimento do parecer somente será dado ao candidato na data informada no item

14.6.2 O teor do parecer motivado será de acesso restrito ao candidato, nos termos do Art. 31 da Lei 12.527/2011.

14.6.3 As deliberações da Comissão de Verificação de Cor-Etnia terão validade apenas para o Processo Seletivo para o qual foi designada, não servindo para outras finalidades.

14.6.4 É vedado à Comissão de Verificação de Cor-Etnia deliberar na presença dos candidatos.

A análise dos Editais supracitados demostra que houve mudanças significativas no que concerne a concretização das políticas afirmativas, nos três últimos anos. A motivação dessas mudanças é devida principalmente à atuação das comissões. Afinal de contas, mediante a ausência de realização desse trabalho o processo de implantação dessas políticas encontravase bastante fragilizada.

Nessa direção, o CEFET-MG desenvolveu ainda o vídeo institucional denominado “Ações Afirmativas no CEFET-MG: bancas para verificação étnica e racial ${ }^{16 ”, ~ q u e ~ a p r e s e n t a ~}$

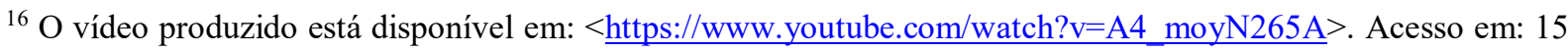
dez. 2019.
} 
Pereira, A. de C.;Silva, N. N. da

o funcionamento das comissões em processos seletivos, além de expor de maneira nítida conceitos como: raça, etnia, fenótipos, autodeclaração étnico-racial, entre outros.

FIGURA 02 - Vídeo Institucional

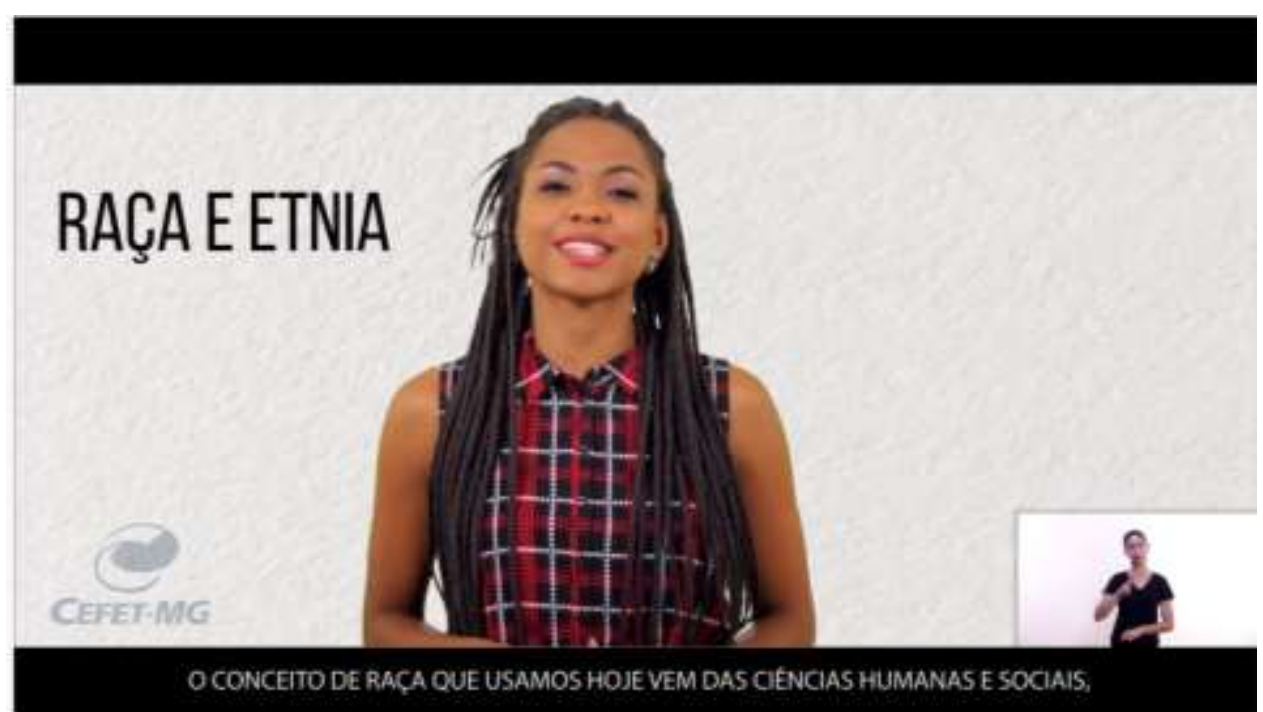

Fonte: CEFET-MG, 2018.

O reconhecimento do trabalho realizado pelas comissões já é notório na instituição investigada. E o seu constante aperfeiçoamento atesta essa compreensão. No entanto, um dos principais desafios verificado nas análises realizadas diz respeito à fragilidade de enraizamento institucional em relação à promoção de uma educação antirracista.

Em outras palavras, não basta apenas garantir o direito de ingresso dos(as) estudantes por meio das ações afirmativas. É preciso também assegurar a sua permanência com qualidade, dignidade e respeito. A atuação desempenhada pelas comissões "[...] só pode ser reconhecida dentro de um projeto afirmativo mais amplo que justifica a construção de critérios editoriais, metodologias, representatividades, enfim, de elementos que ritualizam este fazer comissional" (NUNES, 2018, p.12).

A concretização de um projeto afirmativo envolve, portanto, conceber outros currículos, que sejam capazes de contemplar cosmovisões afro-brasileiras e ameríndias, criar espaços institucionais que acolham as diversidades, adotar práticas de ensino condizentes com os novos sujeitos, estimular e apoiar a constituição de Núcleos de Estudos Afro-brasileiros e Indígenas (NEABI), promover políticas institucionais de assistência estudantil com ênfase nas ações afirmativas, entre outros.

\section{CONSIDERAÇÕES FINAIS}

O estudo revelou que a implementação das comissões de heteroidentificação complementar no CEFET-MG significa uma verdadeira conquista para a efetivação das políticas afirmativas na instituição. 
Pereira, A. de C.;Silva, N. N. da

Nessa perspectiva, a análise documental aponta para a necessidade de constante aprimoramento em relação ao desempenho deste trabalho. Assim sendo, é preciso investir na formação continuada de seus membros. E mais, construir espaços formativos institucionais de modo que seja possível compartilhar experiências adquiridas com toda a comunidade. A adoção dessa e de outras atitudes similares contribui sobremaneira no processo de reeducação das relações étnico-raciais.

Ficou explícito que a responsabilidade por implementar as Políticas de Ações Afirmativas não compete apenas aos membros que atuam nas comissões. Longe disso. Enquanto essas políticas não forem de fato institucionalmente enraizadas o projeto afirmativo abarcado nessas políticas estará fadado a se concretizar parcialmente.

A reflexão advinda do estudo suscitou que as Ações Afirmativas configuram um marco histórico no âmbito das políticas públicas direcionadas a inserção da população estudantil pobre, negra e indígena na educação profissional e superior por parte do Estado. Essa conquista só foi possível devido à luta realizada sobretudo pelo movimento negro e por uma rede solidária antirracista.

O trabalho desempenhado pelas comissões exige enfrentar o racismo institucional que se manifesta de maneira sutil, ambíguo e dissimulado. O processo de implementação das comissões de heteroidentificação complementar carrega portanto consigo possibilidades e potencialidades formativas antirracistas. Nesse caso, a realização desse trabalho necessita acontecer de maneira integrada com todos os setores da instituição.

Em se tratando de promover a valorização da diversidade étnico-racial em um contexto de tradição nas áreas técnicas, a concretização do projeto afirmativo se apresenta ainda mais desafiador.

\section{REFERÊNCIAS}

ANDRÉ, Marli; LUDKE, Menga. Métodos de coleta de dados: observação, entrevista e análise documental. In: ANDRÉ, Marli; LUDKE, Menga. Pesquisa e educação: abordagens qualitativas. São Paulo: E.P.U, 1986. p. 25-45.

BRASIL. Lei $n^{\circ}$. 10.639, de 9 de janeiro de 2003. Altera a Lei n. 9.394, de 20 de dezembro de 1996, que estabelece as diretrizes e bases da educação nacional, para incluir no currículo oficial da Rede de Ensino a obrigatoriedade da temática "História e Cultura Afro-Brasileira", e dá outras providências. Diário Oficial da União, $1^{\circ}$ jan. 2003. Disponível em: < http://www.planalto.gov.br/ccivil_03/leis/2003/110.639.htm>. Acesso em: 13 jun. 2016.

BRASIL. Lei $n^{\circ}$. 11.645, de 10 de março de 2008. Altera a Lei $n^{\circ} .9 .394$, de 20 de dezembro de 1996, modificada pela Lei no 10.639, de 9 de janeiro de 2003, que estabelece as diretrizes e bases da educação nacional, para incluir no currículo oficial da rede de ensino a obrigatoriedade da temática "História e Cultura Afro-Brasileira e Indígena", e dá outras providências. Diário Oficial da União, 25 março. 2008. Disponível em: 
Pereira, A. de C.;Silva, N. N. da

www.planalto.gov.br/ccivil_03/_ato2007-2010/2008/lei/111645.htm - Acesso em: 25 mai. 2015.

BRASIL. Ministério da Educação Conselho Nacional de Educação. Diretrizes curriculares nacionais para a educação das relações étnico-raciais e para o ensino de História e Cultura Afro-brasileira e Africana. Brasília: Ministério da Educação, 2004. Disponível em:

www.sinpro.org.br/arquivos/afro/diretrizes_relacoes_etnico-raciais.pdf - Acesso em: 20 nov. 2015 .

BRASIL. Lei n. 12.711, de 29 de agosto de 2012. Dispõe sobre o ingresso nas universidades federais e nas instituições federais de ensino técnico de nível médio e dá outras providências. Diário Oficial da União, Brasília, DF, 29 ago. 2012. Disponível em http://www.planalto.gov.br/ccivil_03/_ato2011-2014/2012/lei/112711.htm. Acesso em 19 jun. 2018.

BRASIL. Supremo Tribunal Federal. Ação Declaratória de Constitucionalidade $n^{\circ} 41$. Relator: Ministro Roberto Barroso. Diário da Justiça Eletrônico, Brasília, 17 ago. 2017.

BRASIL. Supremo Tribunal Federal. Arguição de Descumprimento de Preceito Fundamental $n^{\circ}$ 186. Relator: Ministro Ricardo Lewandowski. Diário de Justiça Eletrônico, Brasília, 26 abr. 2012 .

CARVALHO, José Jorge de. A política de cotas no ensino superior. Ensaio descritivo e analítico do Mapa das Ações Afirmativas no Brasil. Brasília: Instituto de Inclusão no Ensino Superior e na Pesquisa, CNPQ, Universidade de Brasília, MEC, 2016.

FERES JÚNIOR, João; DAFLON, Verônica Toste; CAMPOS, Luiz Augusto. Ação afirmativa, raça e racismo: uma análise das ações de inclusão racial nos mandatos de Lula e Dilma. Revista de Ciências Humanas, Viçosa, v. 12, n. 2, p. 399-414, jul./dez. 2012.

Disponível em: <https://periodicos.ufv.br/RCH/article/view/3439>. Acesso em: 13 set. 2017.

GOMES, Joaquim Barbosa. Ação Afirmativa \& princípio constitucional da igualdade. Rio de Janeiro: Renovar, 2001.

GOMES, Nilma Lino (Coord.). Práticas pedagógicas de trabalho com relações étnico-raciais na escola na perspectiva da Lei $n^{o}$. 10.639/03. Brasília: MEC/UNESCO, 2012.

GUIMARÃES, Antônio Sérgio. Como trabalhar com "raça" em sociologia. Educação e Pesquisa, São Paulo, v.29, n.1, p. 93-107, jan./jun. 2003. Disponível em:

$<$ https://www.scielo.br/scielo.php?pid=S1517-

97022003000100008\&script=sci_abstract\&tlng=pt $>$. Acesso em: 27 mar. 2017.

GUIMARÃES, Antônio Sérgio. Preconceito de cor e racismo no Brasil. Rev. Antropol., São Paulo, v. 47, n. 1, p. 9-43, 2004. Disponível em:

$<$ https://www.scielo.br/scielo.php?script=sci_arttext\&pid=S0034-

$77012004000100001 \& \operatorname{lng}=\mathrm{en}>$. Acesso em: $10 \mathrm{abr} .2017$.

JORNAL DIAGRAMA. Informativo do Centro Federal de Educação Tecnológica de Minas Gerais. Cotas nas Universidades: história, polêmica e bancas de aferição em pauta dentro e fora do CEFET-MG. N. 03, p.2-12, maio-jun. de 2018. Disponível em: $<$ http://www.secom.cefetmg.br/diagrama/>. Acesso em: 10 nov. 2020.

MACEDO, Rejane Lúcia Amarante. Formação de Professores e Racismo: para onde vamos? Revista Teias v. 21, n. 62, p.106-115, jul./set. 2020. Disponível em: <https://www.epublicacoes.uerj.br/index.php/revistateias/article/view/49740>. Acesso em: 15 out. 2020. 
Pereira, A. de C.;Silva, N. N. da

MEINERZ, Carla Beatriz; PEREIRA, Priscila Nunes. Educação das relações étnico-raciais e superação da branquitude. Identidade! São Leopoldo, v. 23 n. 1, p. 161-180, jan.-jul. 2018. Disponível em: <http://periodicos.est.edu.br/identidade>. Acesso em: 10 set. 2019.

MOEHLECKE, Sabrina. Ação afirmativa: História e debates no Brasil. Cad. Pesqui., São Paulo, n.117, p.197-217, nov. 2002. Disponível em:

$<$ http://www.scielo.br/scielo.php?script=sci_arttext\&pid=S010015742002000300011\&lng=en $\& n r m=$ iso $>$. Acesso em: 17 jan. 2008.

MUNANGA, Kabengele. As ambiguidades do racismo à brasileira. In: KON, Noemi Moritz; SILVA, Maria Lúcia da; ABUD, Cristiane Curi. (Orgs.). O racismo e o negro no Brasil: questões para a psicanálise. São Paulo: Perspectiva, 2017. p.33-44.

NUNES, Georgina Helena Lima. Autodeclarações e comissões: responsabilidade procedimental dos/as gestores/as de ações afirmativas. In: DIAS, Gleidson Renato; TAVARES JUNIOR, Paulo Roberto Faber. Heteroidentificação e cotas raciais: dúvidas, metodologias e procedimentos. Canoas: IFRS, 2018. p. 11-30. Disponível em:

$<$ http://sitio2.com.br/sites/etnicoracial/publicado/chave01/>. Acesso em: 05 de fev. 2019.

OSÓRIO, Rafael. O sistema classificatório de "cor ou raça” do IBGE. Brasília: Ipea, 2003. (Texto para discussão, n.996). Disponível em:

http://www.ipea.gov.br/portal/index.php?option=com_content\&view=article\&id=4212 Acesso em: 20 mar. 2005.

PEREIRA, Aline de Carvalho. Ações afirmativas na educação profissional técnica de ensino médio: Um estudo de caso com jovens estudantes cotistas. 2020. 170f. Dissertação (Mestrado em Educação) - Instituto de Ciências Humanas e Letras, Universidade Federal de Alfenas. 2020.

PIOVESAN, Flávia. Ações afirmativas no Brasil: desafios e perspectivas. Rev. Estud. Fem., Florianópolis, v.16, n.3, p.887-896, dez. 2008. Disponível em $<$ http://www.scielo.br/scielo.php?script=sci_arttext\&pid=S0104026X2008000300010\&lng=pt\&nrm=iso >. Acesso em: 30 set. 2020.

RIOS, Roger Raupp. Pretos e pardos nas ações afirmativas: desafios e respostas da autodeclaração e da heteroidentificação. In: DIAS, Gleidson Renato; TAVARES JUNIOR, Paulo Roberto Faber. Heteroidentificação e cotas raciais: dúvidas, metodologias e procedimentos. Canoas: IFRS, 2018. p. 215-249. Disponível em: $<$ http://sitio2.com.br/sites/etnicoracial/publicado/chave01/>. Acesso em: 05 de fev. 2019.

SANTOS, Adilson Pereira dos; CAMILLOTO, Bruno; DIAS, Hermelinda Gomes. A heteroidentificação na UFOP: o controle social impulsionando o aperfeiçoamento da política pública. Revista da $A B P N$, v. 11, n. 29, p.15-40, jun-ago, 2019. Disponível em: < https://abpnrevista.org.br/index.php/site/issue/view/33>. Acesso em: 10 dez. 2019.

SANTOS, Adilson Pereira dos. Implementação da lei de cotas em três universidades federais mineiras. 2018. 222f. Tese (Doutorado em Educação) - Faculdade de Educação, Universidade Federal de Minas Gerais. 2018. Disponível em:

$<$ https://repositorio.ufmg.br/handle/1843/BUOS-AWKLUJ>. Acesso em 10 jun. 2019.

SILVA, Natalino Neves da Silva. Diversidade étnico-racial e formação de professores no instituto federal de educação, ciência e tecnologia de Minas Gerais - campus Ouro Preto (IFMG/OP). Revista de Educação, Ciência e Cultura, Canoas, v. 24, n. 1, p. 175-186, mar. 2019. Disponível em:

$<$ https://revistas.unilasalle.edu.br/index.php/Educacao/article/view/4494>. Acesso em 08 nov. 2019. 
SILVA, Natalino Neves da Silva. As políticas de Ações Afirmativas no Ensino Superior são um problema? In: Marta Gouveia Rovai (Org.). Revisionismos: a universidade esclarece. São Paulo, Mentes Abertas, 2020. p. 153-174.

SILVA, Petronilha Beatriz Gonçalves; SILVÉRIO, Valter Roberto. Educação e Ações Afirmativas: entre a injustiça simbólica e a injustiça econômica. Brasília: Instituto Nacional de Estudos e Pesquisas Educacionais Anísio Teixeira, 2003. Disponível em:

<etnicoracial.mec.gov.br > educacao_acoes_afirmativas>. Acesso em: 10 fev. 2017.

TAVARES JUNIOR Paulo Roberto Faber. Orientações práticas para a implementação da comissão de heteroidentificação em institutos federais de educação (if's). In: DIAS, Gleidson Renato; TAVARES JUNIOR, Paulo Roberto Faber. Heteroidentificação e cotas raciais: dúvidas, metodologias e procedimentos. Canoas: IFRS, 2018. p. 215-249. Disponível em: $<$ http://sitio2.com.br/sites/etnicoracial/publicado/chave01/>. Acesso em: 05 de fev. 2019.

TELLES, Edward. Racismo à brasileira. Rio de Janeiro: Relume Dumará, 2003.

VAZ, Lívia Maria Sant'Anna. As comissões de verificação e o direito à (dever de) proteção contra a falsidade de autodeclarações raciais. In: DIAS, Gleidson Renato; TAVARES JUNIOR, Paulo Roberto Faber. Heteroidentificação e cotas raciais: dúvidas, metodologias e procedimentos. Canoas: IFRS, 2018. p. 32-78. Disponível em:

$<$ http://sitio2.com.br/sites/etnicoracial/publicado/chave01/>. Acesso em: 05 de fev. 2019. 